\title{
Growth volatility and resource curse: does financial development dampen the oil shocks?
}

\begin{abstract}
We assess whether well-developed financial system can moderate the positive association between oil volatility and growth volatility. Using a core sample of 63 oil-producing countries over the period 2000ï 2010, the empirical analysis confirms a negative link between oil terms of trade volatility and growth volatility. In addition, we find evidence that financial development dampens the effect of oil terms of trade volatility.
\end{abstract}

Keyword: Financial development; Oil volatility; Growth volatility 